\title{
Description of an Intensive Residential Aphasia Treatment Program: Rationale, Clinical Processes, and Outcomes
}

\section{INTRODUCTION}

The influence of treatment intensity on treatment response in persons with aphasia (PWA) has received considerable attention in the aphasia treatment literature over the past 15 years. A metaanalysis of 55 aphasia treatment studies conducted by Robey (1998) revealed that treatment gains were greatest when therapy was provided more than two hours per week. In a subsequent review of 10 aphasia treatment studies, Bhogal, Teasell, \& Speechley (2003) reported a positive relationship between treatment intensity and treatment outcomes. More recently, systematic evidenced-based reviews that included 4 RCTs (Kelly, Brady, \& Enderby 2010), and 11 other studies (Cherney, Patterson, Raymer 2011) directly comparing more vs. less intensive treatment schedules reported only modest or equivocal evidence in favor of intensive treatment.

During this same period, changes in reimbursement models have resulted in decreasing lengths of stay for inpatient rehabilitation and an increasing shift to outpatient settings (Ottenbacher et al, 2004). The change to outpatient service delivery has limited access to care for many PWAs who live outside of urban centers or who lack adequate transportation services. For example, despite the exemption of Veterans Healthcare Administration (VHA) enrollees from private pay therapy caps, a search of VHA's Corporate Data Warehouse revealed that of the 10,371 enrollees carrying a diagnosis of aphasia in FY12, only 30\% (3198) received speech-language rehabilitation services, with an average treatment dose of 12 hours.

Within this context, several non-hospital-based intensive aphasia rehabilitation programs have emerged in recent years in an attempt to improve access to services and to maximize patient outcomes (Cherney et al., 2011). In this poster we provide a brief overview and describe the treatment philosophy, clinical processes and clinical outcomes of an intensive, residentiallybased aphasia treatment program operated by the Veterans Healthcare Administration.

\section{OVERVIEW}

This intensive, residentially-based, aphasia rehabilitation program serves community-dwelling Veterans and active duty military personnel nationwide. Participants reside in 3-bedroom residential villas located on the campus of a VA Medical Center for the duration of the 4-week program. During this time, participants receive 25 hours/week of evidenced-based speech and language rehabilitation services provided by licensed SLPs experienced in aphasia assessment and intervention. A total of six program sessions are offered each year with three veterans participating in each session, permitting an annual program capacity of 18 participants per year. Active duty personnel, service-connected, and co-pay exempt Veterans pay no out-of-pocket costs. All other Veterans are charged a $\$ 50$ per day co-pay. The current program admission rate is $49 \%$ with the most common exclusions being unacceptable medical risk (e.g., recent and/or uncontrolled seizures, cardiac arrhythmia) and inability to perform ADLs independently.

evidenced-based practice. 


\section{REFERENCES}

Bhogal SK, Teasell R, Speechley M. (2003). Intensity of aphasia therapy, impact on recovery, Stroke, 34, 987-993.

Bock, K. \& Levelt, W.J. (1994). Language production, in M.A. Gernsbacher (Ed.), Handbook of Psycholinguistics (pp. 945-984), Academic Press: San Diego, CA.

Boyle, M. \& Coelho, C.A. (1995). Application of semantic feature analysis as a treatment for aphasic dysnomia. American Journal of Speech-Language Pathology, 4(4), 94-98.

Cherney, L. R., Doyle, P. J., Hula, W. D., Lommen, G., Pierson, J. M., Rose, M., Worrall, L., \& Wozniak, L.. (Novermber, 2011). Intensive Comprehensive Aphasia Programs: Philosophy, Procedures and Outcomes. 2-hour Seminar. Annual Convention of the American Speech-Language-Hearing Association, San Diego, CA.

Cherney, L. R., Patterson, J. P., \& Raymer, A. M. (2011). Intensity of Aphasia Therapy: Evidence and Efficacy. Current neurology and neuroscience reports, 11(6), 560-569.

Doyle, P. J., Hula, W. D., Austermann Hula, S. N., Stone, C. A., Wambaugh, J. L., Ross, K. B., $\&$ Schumacher, J. G. (2012). Self-and surrogate-reported communication functioning in aphasia. Quality of Life Research, 1-11.

Edmonds, L. A., Nadeau, S. E., \& Kiran, S. (2009). Effect of Verb Network Strengthening Treatment (VNeST) on lexical retrieval of content words in sentences in persons with aphasia. Aphasiology, 23(3), 402-424.

Kagan, A., Black, S. E., Duchan, J. F., Simmons-Mackie, N., \& Square, P. (2001). Training volunteers as conversation partners using" Supported Conversation for Adults with Aphasia"(SCA): a controlled trial. Journal of Speech, Language and Hearing Research, 44(3), 624.

Kay, J., Lesser, R., \& Coltheart, M. (1992). PALPA: Psycholinguistic Assessments of Language Processing in Aphasia. East Sussex, UK: Lawrence Earlbaum Associates.

Kelly, H., Brady, M.C., \& Enderby, P. (2011). Speech and language therapy for aphasia following stroke. Cochrane database of systematic reviews, 5 .

Kendall, D. L., Rosenbek, J. C., Heilman, K. M., Conway, T., Klenberg, K., Gonzalez Rothi, L. J., \& Nadeau, S. E. (2008). Phoneme-based rehabilitation of anomia in aphasia. Brain and language, 105(1), 1-17. 
McNeil, M. R., Doyle, P. J., Fossett, T. R., Park, G. H., \& Goda, A. J. (2001). Reliability and concurrent validity of the information unit scoring metric for the story retelling procedure. Aphasiology, 15(10-11), 991-1006.

Norman, G. R., Wyrwich, K. W., \& Patrick, D. L. (2007). The mathematical relationship among different forms of responsiveness coefficients. Quality of Life Research, 16(5), 815-822.

Ottenbacher KJ, Smith PM, Illig SB, Linn RT, Ostir GV, Granger CV. (2004). Trends in length of stay, living setting, functional outcome, and mortality following medical rehabilitation. Journal of the American Medical Association, 292, 1687-1695.

Porch B. (2001). Porch index of communicative ability. Albuquerque, NM: PICA Programs.

Robey RR. (1998). A meta-analysis of clinical outcomes in the treatment of aphasia, Journal of Speech, Language, and Hearing Research, 41, 172-187.

Swinburn, K., G. Porter, \& Howard, D. (2004). Comprehensive aphasia test. New York: Psychology Press.

Thompson, C., \& Shapiro, L. (2005). Treating agrammatic aphasia within a linguistic framework: Treatment of Underlying Forms. Aphasiology, 19(10-11), 1021-1036.

Turner, S., \& Whitworth, A. (2006). Conversational partner training programmes in aphasia: A review of key themes and participants' roles. Aphasiology, 20(6), 483-510. 
Table 1 displays the sample characteristics of 68 Veterans/active duty military personnel who have completed the program. The sample represents referrals from 16 different Veterans Integrated Service Networks (VISNs), and 33 different states.

\section{CLINICAL PROCESSES}

\section{$\underline{\text { Assessment }}$}

All assessments begin with electronic medical record review and patient, family and provider contacts to determine candidacy. Admission criteria include medical clearance by the program physician and independence in mobility and ADLs. Additional considerations include perceived motivation, family support, mood, predicted tolerance for intensive treatment and prognosis for improvement. Severity and chronicity of aphasia are considered in selecting candidates for admission but are not independent admission criteria. Selected candidates undergo a standardized battery of assessments prior to program entry for purposes of treatment planning. These include the Comprehensive Aphasia Test (Swinburn, Porter, \& Howard, 2004), connected speech samples (McNeil et al., 2001), and supplemental tests (e.g., Kay, Lesser, \& Coltheart, 1992) selected and administered at the discretion of the examining SLP based upon preliminary findings. Two additional measures are also collected at this time for the purposes of outcome evaluation (Doyle et al., 2012).

\section{$\underline{\text { Treatment }}$}

Treatments provided within this intensive program are grounded in current psycholinguistic and cognitive-neuropsychological approaches to aphasia therapy. Participants' language impairments are described in reference to current models of language processing, and treatments motivated by these models are applied to remediate specified deficits. Wherever possible, treatments supported by empirical studies demonstrating treatment efficacy are selected. Examples of such treatments include: Semantic Feature Analysis (Boyle \& Coehlo, 1995), Verb Network Strengthening Treatment, (Edmonds, Nadeau, \& Kiran, 2009), Treatment of Underlying Forms (Thompson \& Shapiro, 2005), and Kendall and colleagues' (2008) phoneme-based rehabilitation program. In addition to sharing a common grounding in psycholinguistic models of fundamental communication processes, these treatments all rely heavily on practice and repeated drilling of tasks organized around relatively discrete units of language. While the particular stimuli used are designed to have social relevance for a given patient, the focus of treatment is on improving the underlying cognitive-linguistic processes, rather than on language performance in a particular social context.

In addition to the core focus on drills motivated by psycholinguistic models, the program also includes elements of more socially-oriented treatment approaches, including group treatment focused on conversation practice and conversational coaching with patients' significant others or volunteer partners (Turner \& Whitworth, 2006). The primary purpose of these treatment components is to promote generalization of performance gains made in the context of psycholinguistically motivated treatments to other communication partners, and to communication contexts outside of one-on-one client-clinician interactions. A secondary 
purpose, grounded in emerging evidence for the efficacy of socially-oriented treatment approaches (Kagan et al., 2001) is to enhance patients' social participation by improving their communication environment and/or their strategies for overcoming environmental barriers to communication.

\section{OUTCOME MEASURES}

Four standardized outcome measures are collected for purposes of program evaluation. A performance-based measure of overall aphasia severity (Swinburn et al., 2004) and a connected speech sample (McNeil et al., 2001) are obtained at initial evaluation, program entry, and program exit. Patient-reported and surrogate-reported measures of communicative functioning (Doyle et al, 2012) are obtained at initial evaluation, program entry, and 1-3 months following program exit (follow-up). Table 2 describes the outcome measures in more detail.

\section{RESULTS AND DISCUSSION}

For the purposes of this report, aggregated outcome data were analyzed using a four-factor latent growth curve analysis, with a single latent factor specified to represent the initial mean level and mean rate of change for each outcome measure. Cases with complete data for any measure(s) were included. The model was estimated using the robust maximum likelihood estimator in Mplus 7, and fit was adequate $\left(\chi^{2}=74.9,57 \mathrm{df}, \mathrm{p}=0.055, \mathrm{CFI}=0.973\right)$. A series of chi-square difference tests revealed (1) no significant improvement on measures of connected speech, patient-reported functioning, or surrogate-reported functioning between initial evaluation and program entry ( $\mathrm{p}=0.59)$, (2) significant improvement on all four measures between program entry and program exit (all ps < 0.0001), and (3) significantly greater improvement in overall aphasia severity across the treatment interval than across the baseline interval ( $<<0.0001)$. Table 3 displays descriptive data, estimated mean rates of change across the treatment interval, and standardized effect sizes for each measure.

The purpose of this presentation is to describe the clinical outcomes of an intensive aphasia rehabilitation program. The results revealed that for the convenience sample described here, completion of this intensive, residentially-based aphasia treatment program was associated with improvement on both performance-based and self/surrogate-reported outcomes. The limitations of this report will be discussed within the context of the current literature examining the effects of intensive aphasia therapy and evidenced-based practice.

\section{REFERENCES}

Bhogal SK, Teasell R, Speechley M. (2003). Intensity of aphasia therapy, impact on recovery, Stroke, 34, 987-993. 
Bock, K. \& Levelt, W.J. (1994). Language production, in M.A. Gernsbacher (Ed.), Handbook of Psycholinguistics (pp. 945-984), Academic Press: San Diego, CA.

Boyle, M. \& Coelho,, C.A. (1995). Application of semantic feature analysis as a treatment for aphasic dysnomia. American Journal of Speech-Language Pathology, 4(4), 94-98.

Cherney, L. R., Doyle, P. J., Hula, W. D., Lommen, G., Pierson, J. M., Rose, M., Worrall, L., \& Wozniak, L.. (Novermber, 2011). Intensive Comprehensive Aphasia Programs: Philosophy, Procedures and Outcomes. 2-hour Seminar. Annual Convention of the American Speech-Language-Hearing Association, San Diego, CA.

Cherney, L. R., Patterson, J. P., \& Raymer, A. M. (2011). Intensity of Aphasia Therapy: Evidence and Efficacy. Current neurology and neuroscience reports, 11(6), 560-569.

Doyle, P. J., Hula, W. D., Austermann Hula, S. N., Stone, C. A., Wambaugh, J. L., Ross, K. B., \& Schumacher, J. G. (2012). Self-and surrogate-reported communication functioning in aphasia. Quality of Life Research, 1-11.

Edmonds, L. A., Nadeau, S. E., \& Kiran, S. (2009). Effect of Verb Network Strengthening Treatment (VNeST) on lexical retrieval of content words in sentences in persons with aphasia. Aphasiology, 23(3), 402-424.

Kagan, A., Black, S. E., Duchan, J. F., Simmons-Mackie, N., \& Square, P. (2001). Training volunteers as conversation partners using" Supported Conversation for Adults with Aphasia"(SCA): a controlled trial. Journal of Speech, Language and Hearing Research, 44(3), 624.

Kay, J., Lesser, R., \& Coltheart, M. (1992). PALPA: Psycholinguistic Assessments of Language Processing in Aphasia. East Sussex, UK: Lawrence Earlbaum Associates.

Kelly, H., Brady, M.C., \& Enderby, P. (2011). Speech and language therapy for aphasia following stroke. Cochrane database of systematic reviews, 5.

Kendall, D. L., Rosenbek, J. C., Heilman, K. M., Conway, T., Klenberg, K., Gonzalez Rothi, L. J., \& Nadeau, S. E. (2008). Phoneme-based rehabilitation of anomia in aphasia. Brain and language, 105(1), 1-17.

McNeil, M. R., Doyle, P. J., Fossett, T. R., Park, G. H., \& Goda, A. J. (2001). Reliability and concurrent validity of the information unit scoring metric for the story retelling procedure. Aphasiology, 15(10-11), 991-1006.

Norman, G. R., Wyrwich, K. W., \& Patrick, D. L. (2007). The mathematical relationship among different forms of responsiveness coefficients. Quality of Life Research, 16(5), 815-822. 
Ottenbacher KJ, Smith PM, Illig SB, Linn RT, Ostir GV, Granger CV. (2004). Trends in length of stay, living setting, functional outcome, and mortality following medical rehabilitation. Journal of the American Medical Association, 292, 1687-1695.

Porch B. (2001). Porch index of communicative ability. Albuquerque, NM: PICA Programs.

Robey RR. (1998). A meta-analysis of clinical outcomes in the treatment of aphasia, Journal of Speech, Language, and Hearing Research, 41, 172-187.

Swinburn, K., G. Porter, \& Howard, D. (2004). Comprehensive aphasia test. New York: Psychology Press.

Thompson, C., \& Shapiro, L. (2005). Treating agrammatic aphasia within a linguistic framework: Treatment of Underlying Forms. Aphasiology, 19(10-11), 1021-1036.

Turner, S., \& Whitworth, A. (2006). Conversational partner training programmes in aphasia: A review of key themes and participants' roles. Aphasiology, 20(6), 483-510. 
Table 1. Patient Demographic and Clinical Descriptive Data $(\mathbf{N}=68)$

\begin{tabular}{lc}
\hline Gender, \% Male & $91 \%$ \\
Age at Program Entry, Mean (SD) & $55(15)$ \\
Years of Education, Mean (SD) & $14(2.4)$ \\
Months Post Onset at Program Entry, Mean (SD) & $38(42)$ \\
Months Elapsed between Initial Evaluation and & $4(2.7)$ \\
Program Entry, Mean (SD) & \\
Etiology Of Aphasia (\%) & \\
$\quad$ Left Hemisphere Stroke & $90 \%$ \\
$\quad$ Bilateral Stroke & $1.5 \%$ \\
$\quad$ Closed Head Injury & $4 \%$ \\
$\quad$ Penetrating Head Injury & $3 \%$ \\
$\quad$ Herpes Encephalitis & $1.5 \%$ \\
Motor Speech Diagnosis & \\
$\quad$ No Motor Speech Disorder & $66 \%$ \\
$\quad$ Apraxia of Speech & $22 \%$ \\
Dysarthria & $6 \%$ \\
AOS and Dysarthria & $3 \%$ \\
Undetermined Motor Speech Disorder & $3 \%$ \\
Mean (SD) Comprehensive Aphasia Test & \\
Modality Mean T-score at Initial Evaluation & $48.9(6.2)$ \\
\hline
\end{tabular}


Table 2. Description of Program Outcome Measures.

\begin{tabular}{|c|c|c|c|}
\hline Type of Outcome & Assessment Tool & Score Type & Reference Population \\
\hline Patient-Reported & $\begin{array}{l}\text { Aphasia Communication } \\
\text { Outcome Measure (ACOM) }\end{array}$ & $\begin{array}{l}\text { Norm- } \\
\text { referenced, } \\
\text { normalized } \\
\text { T-score }\end{array}$ & $\begin{array}{l}\text { Reference population } \\
\text { consisted of } n=329 \\
\text { participants with } \\
\text { aphasia recruited in the } \\
\text { initial field trial of the } \\
\text { ACOM. }\end{array}$ \\
\hline Surrogate-Reported & $\begin{array}{l}\text { Aphasia Communication } \\
\text { Outcome Measure (ACOM) }\end{array}$ & $\begin{array}{l}\text { Norm- } \\
\text { referenced, } \\
\text { normalized } \\
\text { T-score }\end{array}$ & $\begin{array}{l}\text { Reference population } \\
\text { consisted of } n=329 \\
\text { surrogates for } \\
\text { participants with } \\
\text { aphasia recruited in the } \\
\text { initial field trial of the } \\
\text { ACOM. }\end{array}$ \\
\hline Connected Speech & $\begin{array}{l}\text { Story Retell Procedure } \\
\text { (SRP) }\end{array}$ & $\begin{array}{l}\text { Criterion } \\
\text { referenced, } \\
\% \\
\text { information } \\
\text { units } \\
(\% \text { IUs) }\end{array}$ & $\begin{array}{l}\text { No reference } \\
\text { population, analyzed } \\
\text { raw \% information units } \\
\text { retold }\end{array}$ \\
\hline Overall Aphasia Severity* & $\begin{array}{l}\text { Porch Index of } \\
\text { Communicative Ability } \\
\text { (PICA, N = 30) or } \\
\text { Comprehensive Aphasia } \\
\text { Test (CAT, N = 27) }\end{array}$ & $\begin{array}{l}\text { Norm- } \\
\text { referenced, } \\
\text { normalized } \\
\text { T-score }\end{array}$ & $\begin{array}{l}\text { PICA z-scores based on } \\
\text { Porch }(2001) \text { norms } \\
\text { were transformed to } \\
\text { CAT T-score scale via } \\
\text { linear regression } \\
\text { equation based on } \\
\text { paired CAT-PICA data } \\
\text { from } 58 \text { cases collected } \\
\text { at initial evaluation }\left(\mathrm{r}^{2}=\right. \\
0.76)\end{array}$ \\
\hline
\end{tabular}

*Early in the program's history, the PICA was used as the primary performance-based measure of overall aphasia severity. In February 2011, we began using the CAT for this purpose instead. 
Table 3. Descriptive Data, Estimated Mean Percentage Change Scores, and Standardized Effect Sizes for Program Outcome Measures

\begin{tabular}{|c|c|c|c|c|c|c|c|}
\hline $\begin{array}{l}\text { Type of } \\
\text { Outcome }\end{array}$ & $\begin{array}{c}\text { Initial } \\
\text { Evaluation } \\
\text { Mean } \\
\text { (SD) }\end{array}$ & $\begin{array}{l}\text { Program } \\
\text { Entry } \\
\text { Mean } \\
\text { (SD) }\end{array}$ & $\begin{array}{c}\text { Program } \\
\text { Exit/ } \\
\text { Follow-up } \\
\text { Mean } \\
\text { (SD) }\end{array}$ & $\begin{array}{c}\text { Mean \% } \\
\text { Change at } \\
\text { Program } \\
\text { Exit } \\
(95 \% \mathrm{CI})\end{array}$ & $\begin{array}{l}\text { Standardized } \\
\text { Effect Size* }\end{array}$ & $\begin{array}{c}\% \text { of } \\
\text { Patients } \\
\text { with } \\
\text { Change } \\
\text { Score }>0\end{array}$ & $\begin{array}{c}\text { Number of } \\
\text { Patients } \\
\text { Contributing } \\
\text { Data }\end{array}$ \\
\hline $\begin{array}{l}\text { Patient- } \\
\text { Reported } \\
\text { (ACOM T- } \\
\text { score) }\end{array}$ & $\begin{array}{l}44.5 \\
(8.5)\end{array}$ & $\begin{array}{l}45.1 \\
(9.1)\end{array}$ & $\begin{array}{c}49.6 \\
(11.2)\end{array}$ & $\begin{array}{c}11 \% \\
(7 \%, 16 \%)\end{array}$ & 0.62 & $79 \%$ & 41 \\
\hline $\begin{array}{l}\text { Surrogate- } \\
\text { Reported } \\
\text { (ACOM T- } \\
\text { score) }\end{array}$ & $\begin{array}{l}44.6 \\
(9.3)\end{array}$ & $\begin{array}{c}44.3 \\
(10.7)\end{array}$ & $\begin{array}{c}49.5 \\
(11.2)\end{array}$ & $\begin{array}{c}12 \% \\
(7,16 \%)\end{array}$ & 0.55 & $83 \%$ & 41 \\
\hline $\begin{array}{l}\text { Connected } \\
\text { Speech (SRP } \\
\text { \%IUs) }\end{array}$ & $\begin{array}{c}9.2 \\
(10.4)\end{array}$ & $\begin{array}{l}9.5 \\
(9.0)\end{array}$ & $\begin{array}{c}14.7 \\
(12.4)\end{array}$ & $\begin{array}{c}48 \% \\
(32 \%, 64 \%)\end{array}$ & 0.75 & $90 \%$ & 41 \\
\hline $\begin{array}{l}\text { Overall } \\
\text { Aphasia } \\
\text { Severity } \\
\text { (CAT T- } \\
\text { score) }\end{array}$ & $\begin{array}{l}47.6 \\
(5.4)\end{array}$ & $\begin{array}{l}48.4 \\
(5.6)\end{array}$ & $\begin{array}{l}50.4 \\
(6.0)\end{array}$ & $\begin{array}{c}6 \% \\
(5 \%, 7 \%)\end{array}$ & 0.44 & $95 \%$ & 57 \\
\hline
\end{tabular}

* Effect size was calculated as [(group mean post-treatment score) - (group mean of average pretreatment scores)] / (group standard deviation of average pre-treatment scores), and may be interpreted against Cohen's (1998) benchmarks: 0.2-0.5, small; 0.5-0.8 medium; >0.8, large (Norman, Wyrwich, \& Patrick, 2007). 